\title{
Modelling Exchange Rate and Interest Rate Volatility Persistence in Emerging African Economies
}

\author{
Samuel Bright-Kaitoo \\ University of Ghana \\ William Coffie \\ University of Ghana
}

This study investigates volatility persistence of exchange and interest rates in Africa taking into account the rate of volatility decay. Generalized autoregressive conditional heteroscedasticity (GARCH) model is used to estimate volatility persistence for these economies. The results presented in this study suggest that there is volatility persistence in emerging African exchange rate and interest rate markets. Further empirical estimates reveal that rate of volatility decay varies considerably among the economies, for instance, exchange rate volatility in Nigeria diminishes to half of its original size within two months, while it takes approximately 12 months for volatility in Ghana to diminish to half of its original size. The study concludes that exchange and interest rates volatility risk exist in emerging African economies. The results of this study therefore have important implications for international trading, international portfolio diversification, and asset pricing and financial risk management.

Keywords: exchange rate, interest rate, African economies, generalized autoregressive conditional heteroscedasticity (GARCH), volatility persistence

\section{INTRODUCTION}

The swings in exchange rate and interest rate have become one of the topical issues across the globe particularly in Africa where most economies are import dependent rather than being net exporters. The swings in these variables exert various negative effects on the economies, both at the macro and the micro levels. Rashid and Yaqub (2016) explain that modelling and forecasting volatility have crucial economic implications in solving several problems orchestrated by the unpredictable changes in exchange and interest rates such as issues relating to balance of payment, international capital budgeting and trade deficit. Modelling and forecasting volatility of interest rate and exchange rate in Africa became an important issue among researchers since the 1980s following the waned of fixed exchange rate and the shift to flexible exchange rate and the resultant increased volatility in both interest rate and exchange rate.

One of the major assumptions of time series regression in econometrics is the constant error variance, known as homoscedasticity. Empirical evidence in the literature (for instance, Lau et al. (1990) and Kim and Kon (1994) (cited in Coffie, 2015)) reveals that financial time series are characterized by leptokurtosis (distributions with fat tails), skewness (distributions that are not symmetric and skewed to left or right) and volatility clustering (large changes in prices of financial assets tend to followed by large changes, of either 
sign, and small changes tend to be followed by small changes). Also, financial time series exhibit persistence in volatility (time taken for the volatility to move halfway back towards its unconditional mean) and this is treated as risk or uncertainty by financial analysts. For these statistical characteristics of financial time series to be captured, two econometric models are proposed in the literature: the autoregressive conditional heteroskedasticity (ARCH) model by Engle (1982) and the Bollerslev (1986) generalized autoregressive conditional heteroscedasticity (GARCH).

However, it is worth stating that despite the usefulness of the ARCH model, it is overwhelm with certain weaknesses. According to Brooks (2008), the determination of the number of lags of the squared residual to introduce into the model, the number of lags of squared error that would capture the dependence in the conditional variance and the non-negativity constraints might be violated, are some of the major drawbacks of the ARCH model. The ARCH model over-forecast the fluctuations in the sense that the model slowly react to big shocks and volatility from this model persists for short period of time. In effect this model is good for modelling short term volatility rather than modelling long term volatility. To address the problems inherent in the ARCH model, Bollerslev (1986) introduced the generalized autoregressive conditional heteroscedasticity $(\mathrm{GARCH})$ model. Empirical evidence demonstrates that the GARCH $(1,1)$ is robust enough to capture the dynamics in variance over a long period of time (French et al., 1987).

The GARCH $(1,1)$ model measures the extent to which volatility shock today is important for predicting next period's volatility. GARCH $(1,1)$ model is explicitly defined by first (mean) and second (variance) moment's equations. According to Bollerslev (1986), GARCH $(1,1)$ equation is made up of the return process which depends on the mean, $\mu_{t}$ and disturbance term, $\varepsilon_{t}$, which is assumed to be normally distributed with a constant variance, $\sigma^{2}$. Furthermore, the information set that investor can access up to time $t_{-1}$ is given by $\Omega_{t-1}$. This is mathematically represented as:

$r_{t}=\mu+\varepsilon_{t}$

where

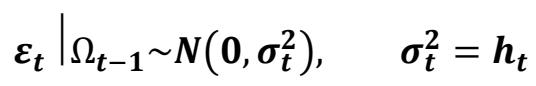

The variance equation (see equation 2) indicates that the conditional variance $h_{t}$ depends on the mean $(\omega)$, information concerning past volatility, $\varepsilon_{t-1}^{2}$ (ARCH term) and the previous variances, $h_{t-1}$ (GARCH term). Thus, GARCH model allows the error term to have a time varying variance conditional on the past behaviour of the series hence reflecting the actual volatilities as perceived by agents. The restrictions $\omega>$ $0, \alpha \geq 0$ and $\beta \geq 0$ are imposed to ensure the parameters $\omega, \alpha$ and $\beta$ are positive. Nevertheless, some studies have shown that negative relationship between return and conditional variance can exist. For instance, Nelson (1991) and Glosten et al. (1993) reported a negative relationship amid return and conditional variance.

$h_{t}=\omega+\alpha \varepsilon_{t-1}^{2}+\beta h_{t-1}$

where

$$
\omega>0, \alpha \geq 0 \text { and } \beta \geq 0
$$

Persistence in volatility is estimated by the sum of $\alpha$ and $\beta$, the level of volatility persistence depends on how fast this sum approaches unity. Interestingly, swings in volatility persist perpetually when $\alpha+\beta=$ 1 . The existence of this attribute implies that today's volatility is crucial for predicting future volatility. Again, when $\alpha+\beta>1$, it is considered to be overshooting volatility which means the swings in volatility at a particular period could result in higher volatility in the subsequent period (Chou (1988) as cited in Coffie (2015)).

Despite the GARCH models' ability to address the problems inherent in ARCH models, some studies have reported some weaknesses characterizing the use of the GARCH model. Brooks (2008) identified 
three key shortfalls of the GARCH models when employed to financial time series as follows: the nonnegativity assumption may be violated, for instance, Black (1976) documented negative nexus between current returns and future volatility which GARCH models postulates that this negative nexus does not exist; GARCH models fails to capture the leverage effects in financial time series; and the GARCH models do not account for direct feedback between the conditional variance and the conditional mean. Although the GARCH model assumes the absence of negativity, some studies have documented negative link amid returns and variance (Coffie, 2015; Nelson, 1991). Lamoureux and Lastrapes (1990), using monte Carlo simulation analyzed daily returns using U. S. data find that GARCH overrate volatility persistence because it does not explain the deterministic structural shifts in the volatility process.

Despite these short falls in the GARCH model, researchers have employed the GARCH model to analyze the behaviour of financial time series especially stock market volatility in both developed and emerging markets. However, little is known on the GARCH model characteristics in modeling exchange rate and interest rate volatility especially in emerging African economies where fundamentals are different from the developed economies. More application of this model is still needed to test or confirm the usefulness of the GARCH model. Based upon this background, the paper investigates the exchange and interest rates volatilities in African economies. In terms of contribution, this study would bring to bear the complexity in recognizing the extent to which interest rate and exchange rate volatilities persists in Africa. This will help African governments to formulate proper monetary and fiscal policies to generate a faster and better economic development. Also, this paper seeks to provide essential information to African's policy makers to formulate policies that would assist in tackling the persistent problem of interest rate and exchange rate volatilities behaviour. Again, this study aims to provide guidance to policy makers and practitioners in planning since this study exposes the rate of decay in the volatility of exchange rate and interest rate. Majority of the studies (e.g., Ebiringa \& Anyaogu, 2014; Abdalla, 2012) have proved that it is inadequate to focus on only the volatility of exchange rate for policy formulation. Therefore, this study considers both volatility in interest rate and exchange rate. This will further provide an in-depth understanding of the mechanism of these two variables in crafting a sustainable monetary policy that will engender development and competitive of African economies. Furthermore, another contribution of this study is that financial institutions and other corporations will be able to take well informed retroactive actions to the swings in interest rate and exchange rate so as to lessen the losses caused by volatility in these variables. In addition, it will enable investors in capital and foreign exchange markets to be able to accurately predict the trend on interest rate and foreign exchange rate in order to make the right investment in Africa.

\section{EVOLUTION AND CURRENTS TRENDS IN EXCHANGE RATE IN AFRICA}

Exchange rate volatility is the unforeseen swings in exchange rate over a specified period of time (Ozturk, 2006). The Bretton Woods Agreement of 1944 dominated the exchange rate policy in Africa from 1946 to 1973. The Bretton Woods Agreement came under serious criticisms in the late 1960s. As a result, the concept of fixed exchange regime was foregone by most developed economies in Europe. Therefore, there was a switched to floating exchange rates while others pegged their domestic currencies to some major currencies such US dollar and UK Pounds.

The inception of the IMF and World Bank Stabilization and Structural Adjustment Programmes in the 1980s triggered a shift in developing economies' exchange-rate regimes. According to Quirk et al. (1987), the IMF suggested a shift from fixed exchange rate regime to floating exchange rate regimes to economies that were having balance of payments challenges. Hence, in the 1990s, majority of programmes and policy embarked on by IMF and World Bank were geared towards exchange rate policies. By the year 2008, most African economies were using the flexible exchange rate regime.

A plot of the monthly exchange rate for some selected African countries over the period January 1991 to September 2014 in Figure 1 shows that, in all four countries, exchange rates have undergone changes in volatility over the period. However, peculiarities exist among these countries. South Africa Rand seems to be the currency that is highly volatile, reaching its peak in September 2001. But the instability shifts 
severally, from high to low and back to high towards the end of the study years. In the case of Namibia, the swings in exchange rate were moderate throughout the beginning of the study period till 28th September 2001 in which volatility increased. While in Egypt the swing appears to increase around 2000. Still in others (Ghana) the fluctuations were prevalent throughout the study period.

\section{FIGURE 1
SWINGS IN SOME AFRICAN COUNTRIES EXCHANGE RATE}

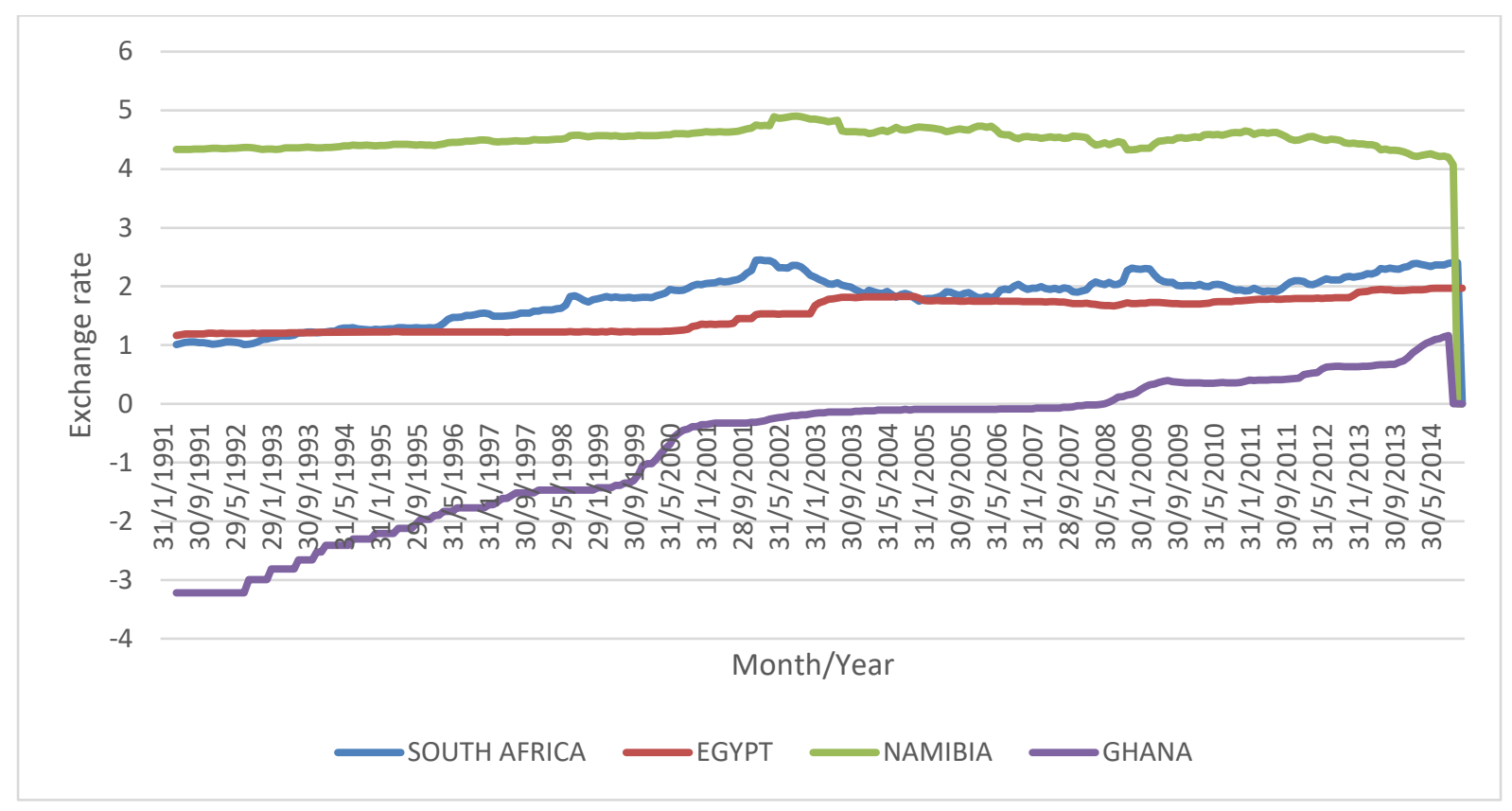

\section{CURRENTS TRENDS IN INTEREST RATE IN AFRICA}

This study uses 30-day interbank interest rate for all selected countries. We present the data about the behaviour of interest rate for some countries from January 1991 to April 2014. Ghana's interest rate appears to be extremely unstable. It, however, becomes stable at specific years, namely 1995 to 1997, 1999 to 2001. This is not likely to be influenced by the swings in exchange rate because while Ghana's interest rate experiences stability, its exchange rate instability continuous to soar up around those periods (see Figure 1). The interest rate for these countries seems to be sensitive to serious international financial crunches (see Figure 2). For instance, Ghana's interest rates for the most part are affected by the 2008/9 global financial crisis. In fact, all the four selected African countries were affected by this crisis as the data show interest rates for each country peaked around the period of the crisis. Though interest rate in Namibia appears higher than South Africa, it moved in tandem with the South African interest rate. However, interest rate of Egypt seems to exhibit some stability throughout the period except around the crisis period. Overall, Ghana's interest rate appears very high and most volatile among the four countries under review. 
FIGURE 2

SWINGS IN SOME AFRICAN COUNTRIES INTEREST RATE

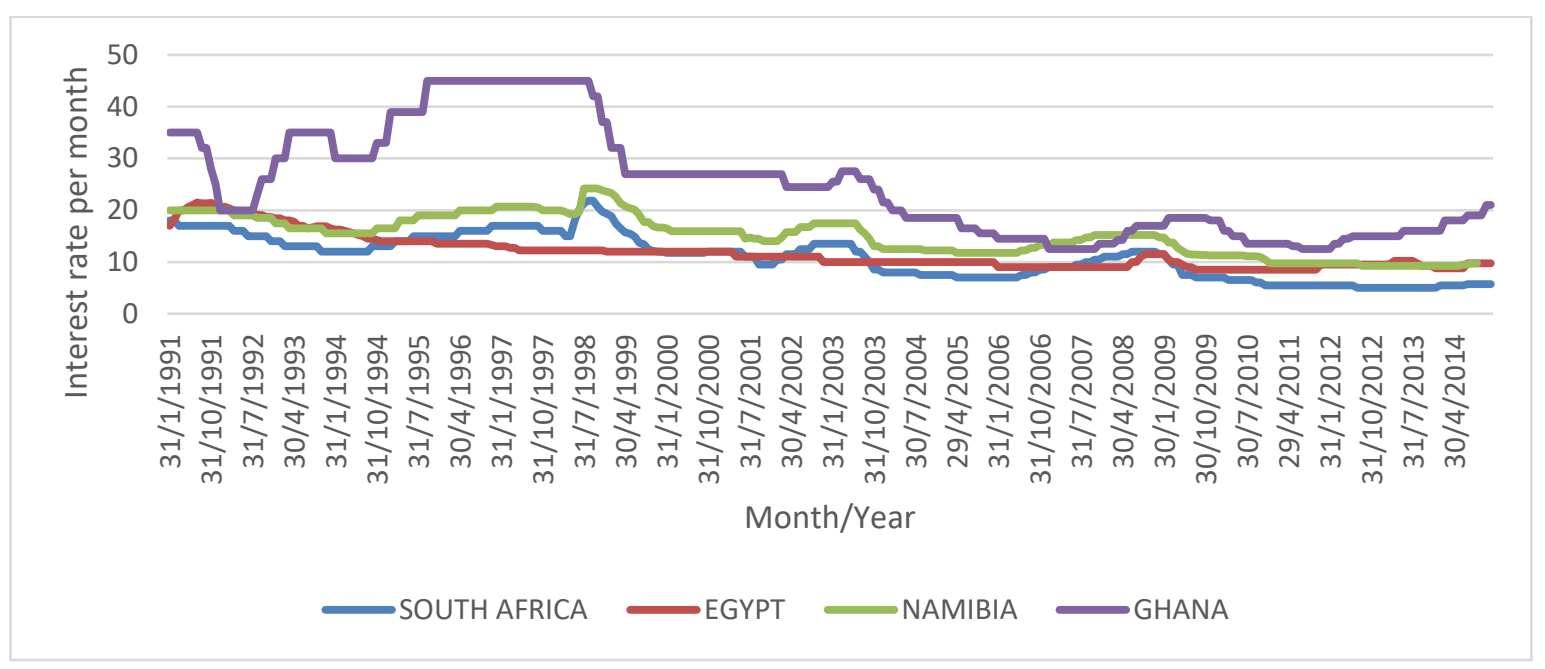

\section{DATA AND METHODOLOGY}

\section{Data Description}

This study uses monthly data on interbank interest rate and bilateral real exchange rates for the domicile currencies of some selected countries vis-a-vis the U.S. dollar to study the volatility behaviour of these variables. The data was obtained from the Reuters DataStream. This source provides an easy and convenient means for the data collection and according to Coffie (2015), Reuters DataStream is reported in the literature to have provided correct and updated data to several researchers and financial analysts for several decades and has made error corrections to past data when there is concrete evidence to take such an action. To obtain robust findings, data was obtained from all the four regional blocks in Africa, specifically, North Africa, South Africa, East and West Africa countries. Thus, Namibia, South Africa, Botswana and Mauritius are the representatives for the Southern Africa regional block; Egypt, Morocco and Tunisia represent the North Africa regional block; Ghana, Nigeria, Ivory Coast and Burkina Faso represent the West Africa regional block; and Kenya represent the East Africa regional block.

TABLE 1

EXCHANGE RATE DATA PROFILE

\begin{tabular}{ccc}
\hline & Currency & Period of data \\
\hline Southern Africa & & \\
Namibia & Dollar & $1991 \mathrm{M} 1-2014 \mathrm{M} 10$ \\
South Africa & Rand & $1960 \mathrm{M} 1-2014 \mathrm{M} 11$ \\
Botswana & Pula & $2005 \mathrm{M} 1-20014 \mathrm{M} 12$ \\
Mauritius & Rupee & $1998 \mathrm{M} 09-2014 \mathrm{M} 12$ \\
Eorthern Africa & & \\
Egypt & Pound & $1994 \mathrm{M} 12-2014 \mathrm{M} 12$ \\
Morocco & Dirham & $1999 \mathrm{M} 1-2014 \mathrm{M} 12$ \\
Tunisia & Dinar & 2000M1 - 2014M12 \\
\hline
\end{tabular}




\begin{tabular}{ccc}
\hline Western Africa & & \\
Ghana & Cedis & 1990M1 - 2014M9 \\
Nigeria & Naira & 1991M1 - 2014M11 \\
Ivory Coast & CFA Franc & 2004M1 - 2014M12 \\
Eastern Africa & Shillings & $1993 \mathrm{M} 1-2014 \mathrm{M} 12$ \\
\hline
\end{tabular}

Note: The table displays the country, currency and sample period for the selected countries.

TABLE 2

INTEREST RATE DATA PROFILE

\begin{tabular}{lcc}
\hline & & Period of data \\
\hline Southern Africa & Namibia & \\
& South Africa & 1991M1 - 2014M09 \\
& Botswana & $1957 \mathrm{M} 1-2014 \mathrm{M} 11$ \\
& Mauritius & $1976 \mathrm{M} 8-20014 \mathrm{M} 12$ \\
Northern Africa & & $1998 \mathrm{M} 4-2011 \mathrm{M} 02$ \\
& Egypt & $1964 \mathrm{M} 1-2014 \mathrm{M} 12$ \\
& Morocco & $1995 \mathrm{M} 6-2014 \mathrm{M} 12$ \\
\multirow{2}{*}{ Western Africa } & Tunisia & $1988 \mathrm{M} 1-2014 \mathrm{M} 12$ \\
& Ghana & $1990 \mathrm{M} 7-2014 \mathrm{M} 12$ \\
& Nigeria & $2002 \mathrm{M} 1-2014 \mathrm{M} 11$ \\
& Ivory Coast & $2005 \mathrm{M} 9-2014 \mathrm{M} 12$ \\
\multirow{2}{*}{ Eastern Africa } & Burkina Faso & $2005 \mathrm{M} 9-2014 \mathrm{M} 12$ \\
& Kenya & $2004 \mathrm{M} 7-2014 \mathrm{M} 12$ \\
\hline
\end{tabular}

Note: The table displays the country, and sample period for the selected countries.

The rate of change (ROC) of exchange rate and rate of change of interest rate, $r_{t}$, is defined as $\left(\left[p_{t} / p_{t-1}\right]\right) * 100$, where $p_{t}$ and $p_{t-1}$ are contemporaneous and one period lagged exchange rate and interest rate prices. In terms of the exchange rate, data included in the calculation of ROC are until December 2014, with the exception of Namibia, South Africa, Ghana and Nigeria. Similarly, with the exception of Namibia, South Africa, Mauritius and Nigeria, the interest rate data employed for the paper are until December 2014. However, the commencement date for the respective time series for each country is variable (see Table 1 and Table 2).

\section{Empirical Framework}

Empirical evidence in the literature has revealed that a higher $\mathrm{ARCH}$ model is required for the dynamics of the conditional variance to be captured. However, it is demonstrated empirically in the literature that GARCH $(1,1)$ model is enough to capture the dynamics of the variance over a period of time by reducing the number of estimated parameters through non-linear restrictions (Franses \& Van Dijk, 1996). In this paper, following Coffie (2015), the heteroscedastic conditional volatility of ROC of exchange rate and interest rate, $r_{t}$, is modeled using $\operatorname{GARCH}(1,1)$ as follows:

$r_{i t}=\mu_{i}+\varepsilon_{i t}$
$\varepsilon_{i t} \mid \Omega_{i t-1} \sim N\left(0, \sigma_{i t}^{2}\right), \sigma_{i t}^{2}=h_{i t}$ 
The ROC process for country $i, r_{i t}$, is captured by the mean equation which is made up of the conditional mean, $\mu_{i}$, which encompasses of autoregressive (AR) and moving average (MA) and the error term $\varepsilon_{i t}$ (see equation 3 ). The ROC process, $r_{i t}$, is the rate of change of exchange rate and interest rate for country $i$ at month $\mathrm{t}$, defined as $\left[\left(\mathrm{p}_{\mathrm{t}} / \mathrm{p}_{\mathrm{t}-1}\right)-1\right] * 100, N$ represents the conditional normal density with mean (zero), and variance $\left(h_{i t}\right)$ and $\Omega_{t}$ is the information set available up to $t-1$.

$h_{i t}=\omega_{i}+\alpha_{i} \varepsilon_{i t-1}^{2}+\beta_{i} h_{i t-1}+v_{i t}$
$\omega_{i}>0, \alpha_{i} \geq 0, \beta_{i} \geq 0, \alpha_{i}+\beta_{i} \geq 0$

The variance equation assumes that conditional variance relies on the lagged squared error term $\left(\varepsilon_{i t-1}^{2}\right)$ and the lagged conditional variance $\left(h_{i t-1}\right)$ and $v_{i t}$ is error of the empirical variance equation (see equation 4). The $\omega_{i}$ (intercept or constant), $\alpha_{i}$ and $\beta_{i}$ are the coefficients to be estimated.

The magnitude of the parameters, $\alpha$ and $\beta$ determine both the short and long run dynamics of the resulting volatility respectively. For instance, a large value of $\beta$ (close to one) implies that shocks to volatility take a longer time to decay and a large $\alpha$ value implies that the volatility reacts quite intensely to markets movements and represents short-run persistence of shocks (Coffie, 2015). Coffie (2015) indicates that if $\alpha+\beta$ is close to 1 , the persistence of fluctuations to volatility is greater and when $\alpha+\beta$ is equal to 1 , then fluctuation to volatility is considered to be permanent. Thus, the degree of exchange rate or interest rate volatility is determined by the autoregressive root, which governs the persistence of volatility shocks. Permanent persistence in fluctuations to volatility means that current period volatility is important in forecasting future volatility. Also, Volatility is considered to be explosive when $\alpha+\beta>1$ which implies that shocks to volatility in one period leads to greater volatility in the next period.

In the literature, researchers have recently focused on estimating the half-lives of volatility persistence in financial markets (McMillan \& Thupayagale, 2009; Coffie, 2015). The half-life measures the number of days or weeks or months at which a shock to volatility will decay to half of its original size and this is computed as:

$\Psi=\frac{\log (0.5)}{\log (\alpha+\beta)}$

Therefore, equation (5) is adopted to examine the number of months at which a shock to the rate of change in exchange rate and interest rate decays to half of its original size.

\section{Descriptive Statistics of Rates}

The summary statistics on exchange rate reveals that Ivory Coast records the highest exchange rate mean with a mean of $496.897 \%$ followed by Nigeria with a mean value of $94.804 \%$, while Botswana records the lowest mean $(0.147 \%)$. Comparing the blocks of African economies, the West Africa economies record both the highest mean and the second highest mean with respect to exchange rate. Volatility of the exchange rate as measured by the standard deviation varies considerably among the African economies under consideration. 
TABLE 3

SUMMARY STATISTICS OF RATES

\begin{tabular}{|c|c|c|c|c|c|}
\hline & Mean & Std. dev. & Skew. & Kurt. & $J-B$ \\
\hline \multicolumn{6}{|c|}{ Panel A: Descriptive Statistics of Exchange Rate Returns } \\
\hline Namibia & 92.51419 & 14.121 & 0.695 & 3.530 & $26.364^{* * *}$ \\
\hline South Africa & 3.463 & 3.133 & 0.839 & 2.371 & $88.251^{* * *}$ \\
\hline Botswana & 0.147 & 0.025 & 0.715 & 3.835 & $13.727^{* * *}$ \\
\hline Mauritius & 29.694 & 2.261 & -0.438 & 2.622 & 7.428304 \\
\hline Egypt & 5.057 & 1.246 & -0.188 & 1.640 & $19.998^{* * *}$ \\
\hline Morocco & 9.047 & 1.124 & 0.890 & 2.911 & $25.42414^{* * *}$ \\
\hline Tunisia & 1.399 & 0.143 & 0.831 & 3.329 & $21.51317^{* * *}$ \\
\hline Ghana & 0.777 & 0.689 & 0.985 & 3.797 & $55.909^{* * *}$ \\
\hline Nigeria & 94.809 & 55.650 & -0.458 & 1.497 & $37.041^{* * *}$ \\
\hline Ivory Coast & 496.897 & 38.805 & 1.964 & 16.213 & $1045.010^{* * *}$ \\
\hline Kenya & 72.216 & 11.687 & -0.619 & 3.044 & $16.879^{* * *}$ \\
\hline \multicolumn{6}{|c|}{ Panel B: Descriptive Statistics of Interest Rate Returns } \\
\hline Namibia & 15.122 & 3.887 & 0.129 & 2.080 & $10.840^{* * *}$ \\
\hline South Africa & 9.290 & 4.797 & 0.682 & 2.368 & $65.608^{* * *}$ \\
\hline Botswana & 10.973 & 3.073 & -0.182 & 1.606 & $39.891^{* * *}$ \\
\hline Mauritius & 7.089 & 3.154 & 0.133 & 1.946 & $9.261^{* * *}$ \\
\hline Egypt & 10.064 & 3.875 & 0.412 & 2.908 & $17.529^{* * *}$ \\
\hline Morocco & 4.124 & 1.355 & 1.023 & 2.501 & $43.431^{* * *}$ \\
\hline Tunisia & 6.857 & 2.516 & 0.734 & 2.230 & $37.083^{* * *}$ \\
\hline Ghana & 25.039 & 10.402 & 0.661 & 2.273 & $27.873^{* * *}$ \\
\hline Nigeria & 11.861 & 3.625 & 0.265 & 2.795 & 2.098575 \\
\hline Ivory Coast & 10.853 & 0.178 & -0.071 & 1.316 & $13.335^{* * *}$ \\
\hline Burkina Faso & 10.961 & 0.614 & -0.421 & 3.203 & 3.501 \\
\hline Kenya & 9.430 & 2.946 & 1.477 & 5.262 & $72.673^{* * *}$ \\
\hline
\end{tabular}

Note: Std. dev. = Standard deviation; Skew. =Skewness; Kurt = Kurtosis; J-B = Jarque-Bera; *** implies statistically significant at $1 \%$

Nigeria registers the highest volatility (as measured by standard deviation) at $55.650 \%$, while Ivory Coast records the second most volatile exchange rate market with volatility at $38.805 \%$. Botswana registers the lowest volatility value at $0.025 \%$ (see Panel A of Table 3). Comparably, it is observed that the volatility of exchange rate is high for Western African economies.

With respect to interest rate, Ghana records the highest interest rate mean at $25.039 \%$ while Mauritius recorded the lowest minimum value. Standard deviation of the change in interest rate as a measure of volatility varies across all the sampled African countries. Specifically, Ghana records the most volatile interest rate at 10.402\%, however, Ivory Coast records the lowest at $0.178 \%$ (see Panel B of Table 3).

\section{EMPIRICAL RESULTS AND ANALYSIS}

According to Coffie (2015), the GARCH model is documented in the literature to have the following three fundamental proposition: the $w>0$ and $\alpha, \beta \geq 0$ to ensure that the conditional variance is strictly positive in relation to expected rate of change; shocks to volatility decay at a constant rate and the speed of decay is measured by the sum of $\alpha$ and $\beta$; and that the sum of $\alpha$ and $\beta$ measures volatility persistence which basically means the degree at which shocks to current volatility remain important over a long-period into the future. 
TABLE 4

GARCH $(1,1)$ AND FRACTIONAL DECAY ESTIMATES

\begin{tabular}{|c|c|c|c|c|c|}
\hline & $\omega$ & $\alpha_{1}$ & $\beta_{1}$ & $\alpha_{1}+\beta_{1}$ & $\Psi$ \\
\hline \multicolumn{6}{|c|}{ Panel A: GARCH $(1,1)$ and fractional decay estimates of rate of change of Exchange Rate } \\
\hline \multirow[t]{2}{*}{ Namibia } & 0.001 & 0.267 & 0.853 & 1.120 & \\
\hline & $(0.120)^{*}$ & $(11.954)^{* * *}$ & $(87.388)^{* * *}$ & {$[0.000]$} & \\
\hline \multirow[t]{2}{*}{ South Africa } & 0.071 & 0.502 & 0.672 & 1.174 & \\
\hline & $(11.683)^{* * *}$ & $(13.813)^{* * *}$ & $(48.798)^{* * *}$ & {$[0.000]$} & \\
\hline \multirow[t]{2}{*}{ Botswana } & 1.537 & 0.013 & 0.824 & 0.834 & 3.82 \\
\hline & $(2.541)^{* *}$ & $0.351^{*}$ & $(13.089)^{* * *}$ & [ 0.007$]$ & \\
\hline \multirow[t]{2}{*}{ Mauritius } & 0.030 & 0.268 & 0.780 & 1.048 & \\
\hline & $(3.112)^{* * *}$ & $(4.804)^{* * *}$ & $(32.588)^{* * *}$ & [0.179] & \\
\hline \multirow[t]{2}{*}{ Egypt } & -0.001 & 0.274 & 0.885 & 1.159 & \\
\hline & $(-0.988)^{*}$ & $(11.915)^{* * *}$ & $(163.780)^{* * *}$ & {$[0.000]$} & \\
\hline \multirow[t]{2}{*}{ Morocco } & 0.442 & 0.113 & 0.815 & 0.928 & 9.28 \\
\hline & $(1.594)^{*}$ & $(2.792)^{* * *}$ & $(13.425)^{* * *}$ & [0.179] & \\
\hline \multirow[t]{2}{*}{ Tunisia } & 0.347 & 0.084 & 0.812 & 0.896 & 6.31 \\
\hline & $(1.169)^{*}$ & $(1.551)^{*}$ & $(7.287)^{* * *}$ & [0.227] & \\
\hline \multirow[t]{2}{*}{ Ghana } & 0.940 & 0.077 & 0.870 & 0.947 & 12.73 \\
\hline & $(5.394)^{* * *}$ & $(3.958)^{* * *}$ & $(57.006)^{* * *}$ & {$[0.000]$} & \\
\hline \multirow[t]{2}{*}{ Nigeria } & 150.144 & -0.004 & 0.567 & 0.563 & 1.21 \\
\hline & $(0.800)^{*}$ & $(-7.204)^{* * *}$ & $(1.042)^{*}$ & [ 0.423] & \\
\hline \multirow[t]{2}{*}{ Ivory Coast } & 2.934 & 4.334 & -0.005 & 4.329 & \\
\hline & $(3.789)^{* * *}$ & $(8.406)^{* * *}$ & $(-0.225)^{*}$ & {$[0.000]$} & \\
\hline \multirow[t]{2}{*}{ Kenya } & 0.216 & 0.542 & 0.601 & 1.143 & \\
\hline & $(5.465)^{* * *}$ & $(9.531)^{* * *}$ & $(43.247)^{* * *}$ & [0.003] & \\
\hline \multicolumn{6}{|c|}{ Panel B: GARCH $(1,1)$ and fractional decay estimates of rate of change of Interest Rate } \\
\hline \multirow[t]{2}{*}{ Namibia } & 4.340 & 0.891 & -0.009 & 0.882 & 5.520 \\
\hline & $(17.732)^{* * *}$ & $(9.674)^{* * *}$ & $(-0.667)^{*}$ & {$[0.235]$} & \\
\hline \multirow[t]{2}{*}{ South Africa } & 3.863 & 0.096 & 0.744 & 0.840 & 3.97 \\
\hline & $(4.946)^{* * *}$ & $(5.712)^{* * *}$ & $(16.361)^{* * *}$ & {$[0.000]$} & \\
\hline \multirow[t]{2}{*}{ Botswana } & 2.184 & 0.046 & 0.831 & 0.877 & 5.281 \\
\hline & $(5.012)^{* * *}$ & $(5.656)^{* * *}$ & $(25.802)^{* * *}$ & {$[0.000]$} & \\
\hline \multirow[t]{2}{*}{ Mauritius } & 14.621 & 0.592 & 0.389 & 0.981 & 36.134 \\
\hline & $(3.370)^{* * *}$ & $(2.279)^{* *}$ & $(2.259)^{* *}$ & [0.856] & \\
\hline \multirow[t]{2}{*}{ Egypt } & 0.037 & 0.001 & 0.994 & 0.995 & 138.283 \\
\hline & $(21.909)^{* * *}$ & $(4.647)^{* * *}$ & $(1937.393)^{* * *}$ & {$[0.000]$} & \\
\hline \multirow[t]{2}{*}{ Morocco } & 2.251 & -0.025 & 0.486 & 0.461 & 0.895 \\
\hline & $(3.234)^{* * *}$ & $(-4.089)^{* * *}$ & $(3.008)^{* * *}$ & {$[0.001]$} & \\
\hline \multirow[t]{2}{*}{ Tunisia } & 1.666 & 0.694 & 0.275 & 0.969 & 22.011 \\
\hline & $(11.034)^{* * *}$ & $(4.804)^{* * *}$ & $(4.780)^{* * *}$ & [0.769] & \\
\hline \multirow[t]{2}{*}{ Ghana } & 0.096 & -0.023 & 1.020 & 0.997 & 230.702 \\
\hline & $(5.914)^{* * *}$ & $(-33.697)^{* * *}$ & $(22887.31)^{* * *}$ & {$[0.000]$} & \\
\hline \multirow[t]{2}{*}{ Nigeria } & 10.345 & -0.027 & 0.591 & 0.564 & 1.21 \\
\hline & $(2.592)^{* * *}$ & $(-19.025)^{* * *}$ & $(3.402)^{* * *}$ & {$[0.014]$} & \\
\hline \multirow[t]{2}{*}{ Ivory Coast } & 0.023 & 0.302 & 0.684 & 0.986 & 49.163 \\
\hline & $(3.563)^{* * *}$ & $(1.811)^{*}$ & $(7.992)^{* * *}$ & [ 0.875$]$ & \\
\hline
\end{tabular}




\begin{tabular}{|c|c|c|c|c|c|}
\hline Burkina Faso & $\begin{array}{c}3.717 \\
(3.313)^{* * *}\end{array}$ & $\begin{array}{c}-0.022 \\
(-19.583)^{* * *}\end{array}$ & $\begin{array}{c}0.596 \\
(4.096)^{* *}\end{array}$ & $\begin{array}{c}0.574 \\
{[0.004]}\end{array}$ & 1.25 \\
\hline Kenya & $\begin{array}{c}8.705 \\
(4.543)^{* * *}\end{array}$ & $\begin{array}{c}1.360 \\
(6.351)^{* * *}\end{array}$ & $\begin{array}{c}0.118 \\
(3.267)^{* * *}\end{array}$ & $\begin{array}{c}1.478 \\
{[0.017]}\end{array}$ & \\
\hline
\end{tabular}

Note: Numbers in parentheses ( ) are z-statistics; Half-lives in month, $\Psi$ are computed as $\frac{\log [0.5]}{\log [\alpha+\beta]}$; Under colum five, p-value [ ] are from a Wald test that $\alpha+\beta=1 ; * * * * *$ and $*$ denotes statistical significance at $1 \%, 5 \%$ and $10 \%$ respectively.

The persistence of shocks to volatility becomes greater as the sum approaches 1 and shock to volatility is considered to be permanent if the sum is equal to 1 and volatility is explosive as this sum becomes greater than 1.

It is observed from Table 4 that the variance constant or intercept $\omega$ for all the countries is greater than zero (0) for both the rate of change of exchange and interest rates which supports the proposition that $\omega>$ 0 . The proposition that $\alpha, \beta \geq 0$ for the variance coefficients are supported by the results of most of the sampled African economies while few of these sampled countries results violate this proposition. Specifically, the coefficients on lagged squared residual (ARCH-term or $\alpha$ ) of the exchange rate variance for Nigeria and the interest rate variance for Morocco, Ghana, Nigeria and Burkina Faso are negative. Similarly, Ivory Coast recorded negative lagged conditional variance (GARCH-term or $\beta$ ) for exchange rate and Namibia GARCH-term also violate the ARCH/GARCH models' proposition. However, the sum of the lagged squared error term $(\alpha)$ and the lagged conditional variance $\beta$ of both exchange rate and interest rate are positive for all the countries employed for the study.

The ARCH-term $(\alpha)$ of exchange rates for the sampled African countries, specifically, South Africa, Namibia, Botswana, Mauritius, Egypt, Morocco, Ghana, Nigeria, Ivory Coast and Kenya are highly statistically significant at 1\% level except for Tunisia. Similarly, the interest rate results revealed that South Africa, Namibia, Botswana, Mauritius, Egypt, Tunisia, Morocco, Ghana, Nigeria, Burkina Faso and Kenya recorded a highly significant ARCH-term $(\alpha)$ at $1 \%$ and Mauritius is significant at $5 \%$ significance level. However, Ivory Coast recorded weak significance ARCH-term. It worth indicating that the large ARCHterm $(\alpha)$ means volatility reacts quite intensely to market movements and represents short-run persistence of shocks (Coffie, 2015).

If the lagged conditional variance (the GARCH-term or $\beta$ ) is close to 1 , it implies that shocks to volatility take a longer time to decay. The results revealed that the GARCH-term $(\beta)$ of the exchange rate market for all the sampled African economies are highly significant at $1 \%$ level except for Nigeria and Ivory Coast which are weakly significant. Also, the GARCH-term of the interest rate market for all the sampled African countries are highly significant at $1 \%$ and $5 \%$ levels. Therefore, it is observed from this empirical evidence that there exist volatility in both exchange rate and interest rate markets for all the African countries considered for this study.

The results of the Wald test that $\alpha+\beta=1$ shows the impact of volatility in the exchange rate market is highly significant in South Africa, Namibia, Botswana, Egypt, Ghana, Ivory Coast and Kenya at 1\% significance level. The Wald test shows that the impact of volatility in the interest rate market is significant in South Africa, Botswana, Egypt, Morocco, Ghana, Nigeria, Kenya and Burkina Faso. These results imply that, the restriction that $\alpha+\beta=1$ is rejected for these economies. In the exchange rate market, South Africa, Namibia, Mauritius, Egypt, Ivory Coast and Kenya recorded $\alpha+\beta>1$ which suggest that the conditional variance is an explosive process. However, Botswana, Morocco, Tunisia, Ghana and Nigeria recorded $\alpha+\beta<1$ which indicate that volatility shocks are fairly persistent, Ghana recording 0.947 followed by Morocco and Tunisia at 0.928 and 0.896 respectively while Nigeria recorded the least volatility persistence at 0.556 . Similarly, in the case of the interest rate market, all the emerging economies considered for this study recorded $\alpha+\beta<1$ except for Kenya (1.248) suggesting that the conditional variance in Kenya is an explosive one with Ghana (0.997), Egypt (0.995), Ivory Coast (0.986) and Morocco (0.461) all showing moderate volatility. 
The half-life of volatility decay of exchange rate results shows that Ghana's high volatility persistence translates into a half-life of 12.73 months, followed by Morocco and Tunisia with a half-life of 9.28 and 6.31 respectively. This implies that a shock to volatility in the past will be significant in predicting future volatility over a long period of time. The sum of $\alpha$ and $\beta$ for Namibia, South Africa, Mauritius, Egypt, Ivory Coast and Kenya under the exchange rate market are above one which implies that the conditional variance is an explosive process hence the half-life decay is in perpetuity. Considering the interest rate market, the high volatility persistence of Ghana translates into a half-life of 231 months, followed by Egypt and Ivory Coast with a half-life of 138 and 49 respectively. However, the sum of $\alpha$ and $\beta$ for Kenya under the interest rate market are above one which implies that the conditional variance is an explosive process hence the half-life decay is in perpetuity.

\section{CONCLUSION}

The dynamics of the conditional variance of financial assets is crucial in making rational financial and economic decisions. In the finance literature, it is widely demonstrated that change in the rate of financial asset depicts leptokurtosis, skewness and volatility clustering. Volatility persistence is also one of the major characteristics of financial data and practitioners regard it as risk or uncertainty. $\operatorname{GARCH}(1,1)$ test was employed to model this type of uncertainty in emerging African exchange rate and interest rate markets. Upon this background, the study investigates volatility persistence in Southern, Eastern, Northern and Western African exchange rate and interest rate markets whiles taking into account the rate of volatility decay. The sum of $\alpha+\beta$ for all the sampled economies for both exchange rate and interest rate markets are positive in support of the fundamental proposition of the GARCH model. Among the sampled African exchange rate markets, Ghana recorded the greatest persistence in volatility and this translates into a halflife of 12.7 months. Similarly, among the sampled African interest rate markets, Egypt registered the highest persistence in volatility and translates into a half-life of 173 months.

It important that policy makers and governments in emerging African market direct their efforts towards improving the governance, management, regulation and discipline monetary and fiscal policies in order to stabilise the exchange rate and interest rate in order to promote business growth, economic growth and developments at large. By so doing the cost of raising short-term loans and imports would decrease and increase the competitiveness of local businesses in the international markets. It is also of the view that this finding is an interesting one which contributes to the growing literature on volatility in emerging African economies. However, future studies can consider using daily observations and increase the sample size to include other economies. Also, other studies may focus on comparing the behaviour of these variables in emerging economies and developed economies.

\section{REFERENCES}

Black, F. (1976). Studies of stock price volatility changes. Proceedings of the 1976 Meetings of the American Statistical Association, Business and Economics Statistics Section, pp. 177-181.

Bollerslev, T. (1986). Generalised autoregressive conditional heteroscedasticity. Journal of Econometrics, 31(3), 307-327.

Brooks, C. (2008). Introductory econometrics for finance. Cambridge University Press.

Chou, R.Y. (1988). Persistent volatility and stock returns - some empirical evidence using ARCH. Journal of Applied Econometrics, 3(4), 279-294.

Coffie, W. (2015). Measuring volatility persistence and risk in Southern and East African stock markets. International Journal of Economics and Business Research, 9(1), 23-36.

Franses, P.H., \& Van Dijk, R. (1996). Forecasting stock market volatility using (non-linear) GARCH models. Journal of Forecasting, 15(3), 229-235.

French, K.R., Schwert, G.W., \& Stambaugh, R.F. (1987). Expected stock returns and volatility. Journal of Financial Economics, 19(1), 3-29. 
Glosten, L.R., Jagannathan, R., \& Runkle, D.E. (1993). On the relations between the expected value and the volatility of the nominal excess returns on stocks. Journal of Finance, 48(5), 1779-1801.

Kim, D., \& Kon, S.J. (1994). Alternative models for the conditional heteroscedasticity of stock returns. Journal of Business, 67(4), 563-598.

Lamoureux, C.G., \& Lastrapes, W.D. (1990). Persistence in variance, structural change and the GARCH model. Journal of Business and Economic Statistics, 8(2), 225-234.

Lau, A., Lau, H., \& Wingender, J. (1990). The distribution of stock returns: New evidence against the stable model. Journal of Business and Economic Statistics, 8(2), 217-223.

McMillan, D.G., \& Thupayagale, P. (2009). Measuring volatility persistence and long memory in the presence of structural breaks: Evidence from African stock markets. Managerial Finance, 37(3), 219-241.

Nelson, D.B. (1991). Conditional Heteroscedasticity in Asset Returns: A New Approach. Econometrica, 59(2), 347-370.

Ozturk, I. (2006). Exchange rate volatility and trade: A literature survey.

Quirk, P.J., Christensen, B.V., Mo Huh, K., \& Sasaki, T. (1987). Floating Exchange Rates in Developing Countries: Experience with Auction and interbank Markets. Occasional Paper No. 53, Washington, DC: IMF.

Rashid A., \& Yaqub. (2016). Modelling oil price, exchange rate and interest rate volatility in Pakistan. Kashmir Economic Review, 25(I). 